\title{
COMPARAÇÃO DE TESTADORES NA AVALIAÇÃO DA CAPACIDADE DE COMBINAÇÃO DE FAMÍLIAS S2 DE MILHO-PIPOCA
}

\author{
CARLOS ALBERTO SCAPIM ${ }^{1}$, MÁRCIA REGINA ROYER ${ }^{2}$, RONALD JOSÉ BARTH PINTO ${ }^{1}$, \\ ANTÔNIO TEIXEIRA DO AMARAL JÚNIOR ${ }^{3}$, CLESO ANTÔNIO PATTO PACHECO ${ }^{4}$ e LIA \\ MARA MOTERLE ${ }^{5}$
}

\begin{abstract}
${ }^{1}$ Engenheiros Agrônomos, Professores Associados, Departamento de Agronomia, Centro de Ciências Agrárias, UEM, Av.Colombo, 5790,87020-900, Maringá,PR; E-mail: cascapim@uem.br (autor para correspondência) e rjbpinto@ uem.br

${ }^{2}$ Bióloga, Dr., Departamento de Agronomia, UEM, Av. Colombo, 5790, 87020-900, Maringá, PR; E-mail: marciaroyer@uem.br

${ }^{3}$ Engenheiro Agrônomo, Professor Associado, Universidade Estadual Norte Fluminense, Departamento de Genética, Campos dos Goytacazes, RJ, E-mail:amaraljr@uenf.br

${ }_{4}^{4}$ Pesquisador da EMBRAPA-CNPMS, Caixa Postal 151, CEP 37200-00LSete Lagoas, MG; E-mail:cleso@cnpms. embrapa.br

${ }^{5}$ Eng. Agrônoma, doutoranda do Programa de Pós-Graduação em Agronomia, UEM, Av. Colombo, 5790, 87020900, Maringá, PR; E-mail: Imoterle@hotmail.com
\end{abstract}

Revista Brasileira de Milho e Sorgo, v.7, n.1, p. 83-91, 2008

\begin{abstract}
RESUMO - O objetivo do estudo foi comparar três testadores (híbrido triplo Zélia, híbrido simples IAC 112 e composto CMS 43) para a avaliação da capacidade de combinação de 36 famílias $\mathrm{S}_{2}$ de milho-pipoca provenientes de CMS 43. As famílias foram avaliadas por seu desempenho per se e em seus cruzamentos com os testadores (topcrosses) por meio de quatro látices 6 x 6, com três repetições, instalados na Fazenda Experimental da Universidade Estadual de Maringá, em Iguatemi - PR, durante as épocas de 'safrinha' de 2001 e safra normal de 2001/2002. As capacidades geral e específica de combinação foram estimadas segundo o modelo dialélico parcial. Foram estimadas as heteroses dos topcrosses em relação à média de cada testador, bem como as correlações entre o desempenho das famílias e dos seus respectivos topcrosses. $\mathrm{O}$ testador mais apropriado, tanto para rendimento de grãos como para capacidade de expansão, foi o híbrido triplo Zélia na 'safrinha', e o testador CMS 43 para as duas características, na safra normal.
\end{abstract}

Palavras-chave: Zea mays, topcross, heterose, híbrido.

\section{COMPARISON OF TESTERS IN THE EVALUATION OF COMBINING ABILITY OF S2 FAMILIES IN POPCORN}

\begin{abstract}
The aim of the present study was to compare three testers (three-way hybrid Zélia, single cross hybrid IAC 112 and composite CMS 43) for evaluating general and specific combining ability of thirty six $\mathrm{S}_{2}$ popcorn families obtained from CMS 43. Families were evaluated considering per se and topcrosses performances, in four 6X6 lattices, with three replications. Trials were carried out in the experimental field at Universidade Estadual de Maringá, in Iguatemi, Paraná, in the years 2001
\end{abstract}


and 2002. General and specific combining ability were estimated following the partial diallel model. Heterosis of topcrosses in relation to the mean of each tester as well as the correlation between families performances and respective topcrosses were estimated. Correlation estimates were obtained among four sets of means: the $S_{2}$ families and the three topcrosses sets. Results showed that the more appropriate testers for grain yield and popping expansion were Zélia in 2001 and CMS 43 in 2002.

Key words: Zea mays, topcross, heterosis, hybrids.

O principal objetivo do trabalho do melhorista é selecionar genótipos superiores dentro de uma determinada população. Assim, as técnicas experimentais de seleção a serem aplicadas devem permitir a identificação e a avaliação de materiais genéticos em menor tempo e custo possíveis. Davis (1927) sugeriu que, na avaliação de elevado número de linhagens, essas deveriam ser testadas em topcross, que consiste no cruzamento de um grupo de linhagens com um ou mais testadores, visando eliminar as que não tenham méritos consideráveis, tornando, dessa forma, mais eficientes os trabalhos de desenvolvimento de híbridos. Embora o mérito do método topcross seja aceito para avaliar linhagens, a própria seleção do testador ideal continua sendo um problema para os melhoristas de milho. Um testador, para qualquer programa de desenvolvimento de híbridos, deve oferecer simplicidade no uso, gerar informações que classifiquem corretamente o potencial relativo das linhagens em cruzamento e maximizar o ganho genético (Hallauer \& Miranda Filho, 1995). As avaliações teóricas e experimentais têm sido apresentadas com relação à frequiência de alelos favoráveis, base genética, capacidade geral ou específica de combinação, rendimento per se, número de testadores e grau de parentesco com os materiais avaliados (Aguilar Morán, 1990; Elias et al., 2000; Sawazaki et al., 2000; Ferreira Neto, 2002; Seifert et al., 2006). Estes estudos têm servido como auxílio na escolha dos testadores, mas não têm fornecido respostas satisfatórias a todas as questões, pois, normalmente apresentam resultados contraditórios. O objetivo do presente estudo foi comparar três testadores de bases genéticas distintas quanto à capacidade de combinação e discriminação de 36 famílias S2 de milho-pipoca.

Os híbridos topcrosses de milho-pipoca foram obtidos no município de Maringá-PR, na Universidade Estadual de Maringá, no ano agrícola de 2000/2001. A avaliação destes foi feita na Fazenda Experimental de Iguatemi-PR, da mesma instituição, durante a "safrinha" de 2001 e safra normal de 2001/2002. Foram utilizadas 36 famílias $\mathrm{S}_{2}$ de milho-pipoca provenientes da população CMS 43, obtidas no ano de 2000. Essa população foi sintetizada pelo Centro Nacional de Pesquisa de Milho e Sorgo (CNPMS), da Empresa Brasileira de Pesquisa Agropecuária -EMBRAPA (Pacheco et al., 2001). Como testadores, foram utilizados os materiais CMS 43, Zélia e IAC 112. Os trabalhos foram desenvolvidos em duas etapas: Na primeira foram realizados cruzamentos manuais entre os três testadores e as 36 famílias $\mathrm{S}_{2}$, num esquema de dialelo parcial, em que cada testador foi cruzado com as 36 famílias. A semeadura foi realizada em outubro de 2000. As 36 famílias $S_{2}$, foram consideradas como femininas, sendo, portanto, receptoras de pólen oriundo dos testadores. Foi 
utilizada no plantio a proporção de três fileiras femininas para cada fileira masculina, semeadas de forma intercalar. A segunda etapa consistiu na avaliação dos híbridos topcrosses e das famílias $\mathrm{S}_{2}$ per se. Foram instalados quatro látices triplos 6x6, na safrinha de 2001 e na safra normal de 2001/2002. Adicionalmente, foram incluídos os três testadores per se em cada sub-bloco do látice. Cada parcela experimental foi constituída por uma linha de três metros, com uma distância de $0,90 \mathrm{~m}$ entre linhas e cinco plantas metro- 1 . Foram avaliadas as características capacidade de expansão e rendimento de grãos. A análise estatística dos dados seguiu o modelo linear para os experimentos em látice com recuperação interblocos. Para a análise conjunta em látice, os tratamentos e os ambientes foram considerados aleatórios. Foi utilizada a estimativa da correlação classificatória de Spearman, para verificar o grau de coincidência nas classificações das famílias $\mathrm{S}_{2}$, em função do testador utilizado. A análise do dialelo parcial foi realizada por meio das médias dos tratamentos ajustados, utilizando modelo proposto por Griffing (1956), adaptado por Geraldi e Miranda Filho (1988). Todas as análises supracitadas foram efetuadas no aplicativo computacional GENES (Cruz, 1997). Foi obtida a estimativa da heterose relativa de cada topcross.

Em 2001, para rendimento de grãos (Tabela 1), as famílias que mais se destacaram com base na capacidade geral de combinação foram as de número 3, 7, 14, 29 e 30. Por outro lado, em 2001/2002, foram as famílias de número 4, 7, 17, 22, 23, 28 e 32. Quanto aos testadores, foram encontrados valores positivos da capacidade geral de combinação de CMS 43 e do IAC 112 em 2001. No ano agrícola de 2001/2002, Zélia apresentou estimativa positiva da capacidade geral de combinação.
Em 2001/2002, os maiores valores de capacidade específica de combinação foram observados nos cruzamentos das famílias $11 \mathrm{e}$ 12 com Zélia, das famílias 24 e 15 com CMS 43 e das famílias 27,22 e 23 com IAC 112. Em 2001/2002, os maiores valores de capacidade específica de combinação foram observados nos cruzamentos das famílias $11,15,12$, e 33 com Zélia, das famílias 5, 12, 14 e 29 com CMS 43 e das famílias 23, 10, 26 e 20 com IAC 112. Nota-se que apenas a progênie S2 de número 12 destacou-se, ao mesmo tempo, com mais de um testador nos dois anos agrícolas. As progênies de números 11 e 12 foram identificadas com maior capacidade específica, com mesmo testador, nos dois anos agrícolas. Em 2001/2002, nenhuma progênie com alta capacidade geral de combinação destacou-se na capacidade específica. No ano agrícola de 2002, apenas duas (29 e 14) propiciaram boa capacidade específica de combinação com o testador IAC-112 e a progênie 23 apresentou boa capacidade específica de combinação com o testador CMS 43.

Para a capacidade de expansão, as famílias que mais se destacaram, com base em , foram as de número 3, 21, 15 e 33, nos dois anos agrícolas (Tabela 2). Em 2001, com exceção da família 3, que ocupou a primeira posição, tanto em rendimento como em expansão, as famílias com maior capacidade geral de combinação para rendimento de grãos em 2001 (3, 7, 29, 14 e 30$)$ e em 2001/2002 (7, 32, 28, 22, 23, 17 e 4) não foram as mesmas que se destacaram para capacidade de expansão em 2001 e 2001/2002 (3, 21, 15 e 33). As progênies 14 e 15 também tiveram valores positivos de capacidade geral de combinação para ambos os caracteres, podendo ser aproveitadas pelo programa inclusive pelo fato de se destacarem 
TABELA 1. Estimativas dos efeitos da capacidade geral de combinação ( e ) associados aos grupos I e II para rendimento de grãos, de acordo com o modelo de Griffing (1956), com adaptação de Geraldi \& Miranda Filho (1988). Maringá, 2001 e 2001/2002.

EFEITOS DA CAPACIDADE GERAL DE COMBINAÇÃO ASSOCIADO AS FAMÍLIAS

\begin{tabular}{|c|c|c|c|c|c|}
\hline \multirow{2}{*}{ Famílias } & \multicolumn{2}{|c|}{ Efeitos } & \multirow{2}{*}{ Famílias } & \multicolumn{2}{|c|}{ Efeitos } \\
\hline & 2001 & $2001 / 2002$ & & 2001 & $2001 / 2002$ \\
\hline 1 & $-238,134$ & $-314,267$ & 19 & $-4,373$ & 112,072 \\
\hline 2 & $-152,091$ & $-922,419$ & 20 & $-275,934$ & $-32,188$ \\
\hline 3 & 695,743 & $-305,269$ & 21 & $-437,416$ & $-98,297$ \\
\hline 4 & 21,180 & 413,273 & 22 & 52,693 & 492,105 \\
\hline 5 & $-133,044$ & 14,617 & 23 & $-323,148$ & 488,491 \\
\hline 6 & 174,259 & $-201,515$ & 24 & $-13,752$ & 364,238 \\
\hline 7 & 464,310 & 971,149 & 25 & $-76,704$ & $-349,884$ \\
\hline 8 & $-103,047$ & $-128,622$ & 26 & $-113,178$ & $-323,246$ \\
\hline 9 & $-185,269$ & 180,829 & 27 & $-214,560$ & $-148,102$ \\
\hline 10 & $-60,592$ & 238,942 & 28 & $-266,088$ & 683,802 \\
\hline 11 & $-162,840$ & 224,308 & 29 & 441,670 & $-5,185$ \\
\hline 12 & $-91,770$ & 158,989 & 30 & 405,122 & $-444,896$ \\
\hline 13 & $-85,482$ & $-810,912$ & 31 & $-243,447$ & $-798,912$ \\
\hline 14 & 409,413 & $-480,897$ & 32 & 196,763 & 695,306 \\
\hline 15 & 104,234 & $-544,626$ & 33 & $-171,309$ & $-344,887$ \\
\hline 16 & $-7,589$ & 130,766 & 34 & 180,374 & 158,985 \\
\hline 17 & 46,626 & 458,487 & 35 & $-17,839$ & 362,935 \\
\hline 18 & 226,227 & $-28,412$ & 36 & $-41,100$ & 133,243 \\
\hline Erro padrão $\left(\hat{g}_{i}\right)$ & 97,364 & 100,365 & Erro padrão $\left(\hat{g}_{i}-\hat{g}_{j}\right)$ & 139,647 & 143,951 \\
\hline
\end{tabular}

EFEITOS DA CAPACIDADE GERAL DE COMBINAÇÃO ASSOCIADO AOS TESTADORES

\begin{tabular}{lcc}
\hline \multirow{2}{*}{ Testadores } & \multicolumn{2}{c}{ Efeitos } \\
\cline { 2 - 3 } 1. Zélia & 2001 & 182,929 \\
2. IAC 112 & $-644,540$ & $-62,651$ \\
3. CMS 43 & 292,413 & $-120,278$ \\
\hline Erro padrão $\left(\hat{g}_{i}\right)$ & 352,127 & 23,992 \\
Erro padrão $\left(\hat{g}_{i}-\hat{g}_{j}\right)$ & 23,274 & 41,555 \\
\hline
\end{tabular}


isoladamente em atributos específicos (14 para produção e 15 para capacidade de expansão)

Quanto aos testadores (Tabela 2), denotase, pelos resultados obtidos para , em 2001, que, para capacidade de expansão, Zélia teve maior $\hat{g}_{i}$. No ano agrícola de 2001/2002, IAC 112 superou Zélia e o CMS 43 apresentou, novamente, o menor valor do conjunto. Em 2001, os maiores valores de capacidade específica de combinação, para a característica capacidade de expansão, foram observados nos cruzamentos das famílias 3, 35 e 24 com Zélia e os da família 23, tanto com IAC 112, quanto com CMS 43. Além da família 3, já mencionada, houve destaque para a família 23, a qual demonstrou boa capacidade específica com dois dos três testadores avaliados. Em 2001/2002, os maiores valores de capacidade específica de combinação foram observados nos cruzamentos da família 1 com Zélia, famílias 4 e 24 com IAC 112 e 30 com o CMS 43.

Os baixos valores obtidos da correlação classificatória de Spearman, para rendimento de grãos, nos dois anos agrícolas $(r=0,00$ a 0,40$)$, sugerem que a classificação das famílias foi diferente, de acordo com o testador analisado. Esses resultados confirmam a necessidade de avaliação de diferentes testadores e são coerentes com a significância da capacidade específica de combinação. No entanto, os valores de correlação para rendimento de grãos foram maiores do que alguns valores relatados na literatura disponível em milho (Keller, 1949; Lonnquist \& Rumbaugh, 1958).

No caso da capacidade de expansão, foram observadas correlações mais elevadas do que em rendimento de grãos, encontrandose valores entre 0,50 e 0,76 . Os resultados indicam maior coincidência classificatória entre testadores. Além disso, como já comentado, houve significância da capacidade específica de combinação. Esses elementos não permitem, portanto, que se descarte a possibilidade de ocorrência de discrepâncias entre os testadores. As estimativas de correlação evidenciaram que a associação entre o desempenho das famílias per se e nos topcrosses foi praticamente nula para rendimento de grãos $(r=-0,39$ a 0,26$)$, em todos os casos, e baixa para capacidade de expansão $(r=-0,06$ a 0,45$)$.

A média heterótica dos topcrosses para rendimento de grãos foi negativa para todos os testadores, com apenas três exceções. Esse resultado já era esperado, porque seria pouco provável que os topcrosses pudessem superar o desempenho de uma variedade melhorada ou de híbridos comerciais. Os valores de heterose para capacidade de expansão foram, geralmente, positivos para os topcrosses com CMS 43, em 2001 e, geralmente, negativos em 2001/2002. Para os topcrosses com Zélia e IAC 112, em geral negativos nos dois anos agrícolas, possivelmente em função de dois fatores: a baixa depressão por endogamia das famílias $S_{2}$ para esse caráter e a baixa capacidade de expansão do testador CMS 43 per se. Em 2001/2002, as famílias com melhor desempenho per se foram as de número 3, 7, 22, 24 e 30.

Em 2001, os topcrosses mais destacados com Zélia envolveram as famílias 3, 5 e 21. Analogamente, as famílias 3 e 21 cruzaramse bem com IAC 112, da mesma forma que 21 e 33 apresentaram bons cruzamentos com CMS 43. Em 2001/2002, apenas as famílias 15 e 30 apresentam bons cruzamentos com CMS 43. A heterose para capacidade de expansão geralmente apresenta valores baixos ou até negativos. Assim, é necessário que as linhagens tenham alto índice de expansão, fixando os efeitos heteróticos para serem explorados para 
TABELA 2. Estimativas dos efeitos da capacidade geral de combinação (e ) associados aos grupos I e II para capacidade de expansão, de acordo com o modelo de Griffing (1956), com adaptação de Geraldi \& Miranda Filho (1988). Maringá, 2001 e 2001/2002.

EFEITOS DA CAPACIDADE GERAL DE COMBINAÇÃO ASSOCIADO AS FAMÍLIAS

\begin{tabular}{|c|c|c|c|c|c|}
\hline \multirow{2}{*}{ Famílias } & \multicolumn{2}{|c|}{ Efeitos } & \multirow{2}{*}{ Famílias } & \multicolumn{2}{|c|}{ Efeitos } \\
\hline & 2001 & $2001 / 2002$ & & 2001 & $2001 / 2002$ \\
\hline 1 & $-2,743$ & 3,610 & 19 & $-0,010$ & $-2,586$ \\
\hline 2 & $-2,450$ & $-0,546$ & 20 & $-3,373$ & 0,717 \\
\hline 3 & 7,504 & 4,344 & 21 & 5,640 & 2,817 \\
\hline 4 & $-5,740$ & $-3,690$ & 22 & 1,857 & $-0,750$ \\
\hline 5 & 3,680 & 1,457 & 23 & $-4,253$ & 2,930 \\
\hline 6 & 1,547 & 0,377 & 24 & 0,260 & $-3,823$ \\
\hline 7 & $-1,030$ & $-0,020$ & 25 & 0,770 & 2,360 \\
\hline 8 & 1,904 & $-0,806$ & 26 & 1,950 & 0,010 \\
\hline 9 & 1,417 & 0,477 & 27 & 3,014 & 2,437 \\
\hline 10 & $-1,693$ & 0,750 & 28 & 0,350 & $-0,356$ \\
\hline 11 & $-6,140$ & $-3,856$ & 29 & $-1,210$ & $-0,093$ \\
\hline 12 & $-2,543$ & $-3,270$ & 30 & $-1,163$ & 2,920 \\
\hline 13 & 1,190 & 2,354 & 31 & 0,967 & $-2,893$ \\
\hline 14 & 2,837 & 1,480 & 32 & $-2,807$ & 2,300 \\
\hline 15 & 4,040 & 3,457 & 33 & 4,260 & 2,804 \\
\hline 16 & $-2,120$ & $-0,980$ & 34 & 0,660 & $-3,313$ \\
\hline 17 & $-2,966$ & $-1,176$ & 35 & 1,024 & $-1,410$ \\
\hline 18 & $-1,696$ & $-5,730$ & 36 & $-2,940$ & $-2,310$ \\
\hline o padrão $\left(\hat{g}_{i}\right)$ & 0,801 & 0,932 & Erro padrão $\left(\hat{g}_{i}-\hat{g}_{j}\right)$ & 1,149 & 1,337 \\
\hline
\end{tabular}

EFEITOS DA CAPACIDADE GERAL DE COMBINAÇÃO ASSOCIADO AOS TESTADORES

\begin{tabular}{lcc}
\hline \multirow{2}{*}{ Testadores } & \multicolumn{2}{c}{ Efeitos } \\
\cline { 2 - 3 } & 2001 & 1,182 \\
\hline 1. Zélia & 0,983 & 1,724 \\
2. IAC 112 & 0,447 & $-2,906$ \\
3. CMS 43 & $-1,430$ & 0,223 \\
\hline Erro padrão $\left(\hat{s}_{i}\right)$ & 0,191 & 0,386 \\
Erro padrão $\left(\hat{g}_{i}-\hat{g}_{j}\right)$ & 0,332 & \\
\hline
\end{tabular}


rendimento de grãos e outras características agronômicas.

O nível de coincidência entre os méritos das famílias per se, em relação à média geral de famílias e o mérito dos topcrosses de cada testador, em relação à média geral dos topcrosses, pode servir de parâmetro para a utilização da heterose como critério adicional à escolha do melhor testador. Teoricamente, um bom testador identificaria como superiores aquelas famílias com as quais se cruzou bem, gerando alta heterose em relação ao pai superior, de modo que tal resultado coincida com o desempenho favorável das mesmas famílias per se. Em 2001, a adoção desse critério de concordância entre hierarquia de médias indicou mais uma vez que, para rendimento de grãos, Zélia foi melhor testador do que CMS 43 e que este, por sua vez, foi superior a IAC 112. Por outro lado, porém, os resultados apresentados para expansão não identificaram a superioridade de um testador sobre outro, razão pela qual esse critério não se mostrou adequado para a escolha de testadores, visando maior capacidade de expansão.

Em termos gerais, evidências apresentadas por vários autores (Rawlings \& Thompson, 1962; Allison \& Curnow, 1966) indicam que as linhagens homozigotas recessivas $\mathrm{e}$ as populações com baixa frequência de alelos favoráveis em locos importantes constituem os testadores mais efetivos para discriminar linhagens em programas de milho híbrido e de melhoramento de populações por meio de seleção recorrente. A pressuposição de que o melhor testador de uma linhagem geralmente seja constituído por plantas da própria população de origem dessa linhagem é justificada, teoricamente, porque o uso de tal testador assegura uma seleção efetiva. Em outras palavras, somente nesse caso uma alta frequência de alelos recessivos deletérios, no testador, estaria sempre associada a uma alta frequiência de alelos recessivos no material em teste (Hallauer \& Miranda Filho, 1995). No presente estudo, no ano agrícola de 2001, o fato de CMS 43 apresentar maior que os demais testadores, para rendimento de grãos, indica que sua freqüência de alelos favoráveis seja relativamente alta, não apresentando, portanto, as melhores condições para ser bom testador para esse caráter, pelas razões supracitadas. Em 2002, aconteceu o inverso, o CMS 43 apresentou menor . A explicação mais plausível é a interação dos testadores (CGC) $\mathrm{x}$ anos.

Utilizou-se como critério fundamental para a escolha do melhor testador a coincidência da ordem de seus topcrosses com a classificação da capacidade combinatória das famílias testadas. Verificou-se que, no ano agrícola de 2001, CMS 43 não foi o melhor testador, porque praticamente limitou-se a identificar a melhor família (progênie 3). O testador IAC 112 , por sua vez, identificou todas as seis famílias de maior capacidade combinatória. No entanto, foi penalizado por não ter qualificado devidamente a família 3 , colocando-a em sexto lugar, e também por ter superestimado o mérito da família 14, um material cujos topcrosses não se destacaram com nenhum outro testador. Quanto a Zélia, sua superioridade como testador foi justificada por sua capacidade de identificar quatro entre as seis melhores famílias e pelo fato de que as famílias não identificadas por Zélia (14 e 18) não foram particularmente notáveis em termos de capacidade geral de combinação. Em 2001/2002, os resultados não são tão evidentes como em 2001, pois CMS 43 identificou três das cinco melhores famílias e Zélia, apenas duas. Os resultados obtidos apontam para o predomínio 
da ação gênica aditiva na herança da capacidade de expansão (Pereira \& Amaral Junior, 2001).

Segundo Hallauer \& Miranda Filho (1995), as variedades não aparentadas de baixo desempenho seriam bons testadores somente se o baixo desempenho fosse devido a uma baixa frequiência de alelos favoráveis em locos importantes para a manifestação do caráter. Esse postulado não se aplica ao presente caso, pois os resultados indicaram que tanto os topcrosses com Zélia, como Zélia per se apresentaram capacidade de expansão igual ou superior aos demais testadores. Por outro lado, não parece muito provável que um híbrido triplo com a qualidade de expansão apresentada por Zélia seja portador de uma alta freqüência de alelos deletérios, pois se supõe que as linhagens que o constituem tenham alta capacidade geral de combinação. Assim, a eleição de Zélia como o melhor testador para capacidade de expansão poderia estar comprometida, caso o desempenho de Zélia per se fosse ruim para esse caráter, o que não ocorreu, nos dois anos agrícolas. Para capacidade de expansão, no ano agrícola de 2001, o IAC 112 foi o pior testador, pelo fato de só identificar três das cinco famílias com maior capacidade geral de combinação. Entre Zélia e CMS 43, nesse caso, é provável que Zélia tenha influenciado fortemente a capacidade geral de combinação dessas cinco melhores famílias.

Assim, se, por um lado, é verdade que a maior capacidade geral de combinação de Zélia para o caráter capacidade de expansão indica sua maior freqüência de alelos favoráveis, prejudicando, portanto, suas perspectivas como testador da qualidade da pipoca em famílias parcialmente endogâmicas, por outro, deixa claros os méritos de Zélia no ponto crucial da discussão: o nível de acerto do testador na classificação dos materiais. Para o ano agrícola de 2001/2002, foi possível observar, com base nos resultados obtidos para capacidade de expansão, que CMS 43 apresentou menor capacidade geral de combinação, maior nível de acerto do testador na classificação dos materiais, maior capacidade de discriminação entre os topcrosses e maior correlação. $\mathrm{O}$ uso de testadores diferentes para características distintas tende a complicar o processo de seleção, pois demandaria uma quantidade bem maior de sementes de cada família, exigindo maior volume de mão-de-obra para as autofecundações e cruzamentos, condução de ensaios de campo e realização das avaliações dos diversos caracteres de produção e qualidade de grãos. $\mathrm{O}$ testador mais apropriado, tanto para rendimento de grãos, como para capacidade de expansão, foi o híbrido triplo Zélia, na 'safrinha', e o testador CMS 43, para as duas características, na safra normal.

\section{Literatura Citada}

AGUILAR MORÁN, J. F. Comparação de testadores para avaliação da capacidade de combinação de linhagens de milho (Zea mays L.). 1990. 264 f. Tese (Doutorado em Genética e Melhoramento de Plantas) - Escola Superior de Agricultura "Luiz de Queiroz”, Universidade de São Paulo, Piracicaba.

ALLISON, J. C. S.; CURNOW, R. W. On the choice of tester parent for the breeding of synthetic varieties of maize (Zea mays L.). Crop Science, Madison, v. 6, p. 541-544, 1966.

CRUZ, C. D. Programa GENES: aplicativo computacional em Genética e Estatística. Viçosa: UFV, 1997. 442 p. 
DAVIS, R. L. Report of the plant breeder. Puerto Rico: Agricultural Experiment Station, 1927. p. 14-15.

ELIAS, H. T.; CARVALHO, S. P.; ANDRÉ, C. G. M. Comparação de testadores na avaliação de famílias $S_{2}$ de milho. Pesquisa Agropecuária Brasileira, Brasília, DF, v. 35, n. 6, p. 1135- 1142, 2000.

FERREIRA NETO, A. Comparação de testadores na avaliação de famílias $S_{2}$ de milho pipoca (Zea mays L.). 2002. 63 f. Dissertação (Mestrado em Melhoramento Genético Vegetal) - Universidade Estadual de Maringá, Maringá.

GERALDI, I. O.; MIRANDA FILHO, J. B. Adapted models for the analysis of combining ability of varieties in partial diallel crosses. Brazilian Journal of Genetics, Ribeirão Preto, v. 2, p. 419-430, 1988.

GRIFFING, A.R. Concept of general and specific combining ability in relation to diallel crossing system. Australian Journal of Biological Science, Melbourne, v. 9, p. 463-493, 1956.

HALLAUER, A. R.; MIRANDA FILHO, J. $B$. Quantitative genetics in maize breeding. 2nd. ed. Ames: Iowa State University Press, 1995. 468 p.

KELLER, K.R. A comparison involving the number of and relationships between, testers in evaluating inbred lines of maize. Agronomy Journal, Madison, v. 41, p. 323-331, 1949.

LONNQUIST, J. H.; RUMBAUGH, M. D. Relative importance of test sequence for general and specific combining ability in corn breeding. Agronomy Journal, Madison, v. 50, p. 541-544, 1958.

PACHECO, C. A. P.; GAMA, E. E. G.; PARENTONI, S. N.; SANTOS, M. X.; LOPES, M. A.; FERREIRA, A. S.; FERNANDES, F. T.; GUIMARÃES, P. E. O.; CORREIA, A.; MEIRELLES, W. F.; FELDMAN, R. O.; MAGNAVACA, R. BRS ANGELA - variedade de milho-pipoca. Sete Lagoas: EMBRAPA-CNPMS, 2001. 6 p. (EMBRAPA-CNPMS. Circular técnica, 21).

PEREIRA, M.G.; AMARAL JUNIOR, A.T. Estimation of genetic components in popcorn based on the nested design. Crop Breeding and Applied Biotechnology, Londrina, v.1, n.1, p. 3-10, 2001.

RAWLINGS, J. O.; THOMPSON, D. L. Performance level as criterion for the choice of maize testers. Crop Science, Madison, v. 2, p. 217-220, 1962.

SAWAZAKI, E.; PATERNIANI, M. E. A. G. Z.; CASTRO, J. L.; GALLO, P. BOLLER; GALVÃO, J.C.C.; SAES, L. A. Potencial de linhagens de populações locais de milho-pipoca para síntese de híbridos. Bragantia, Campinas, v. 59, n. 2, p. 143-151, 2000.

SEIFERT, A. L.; CARPENTIERI-PÍPOLO, V.; FERREIRA, J. M.; GERAGE, A. C. Análise combinatória de populações de milho pipoca em topcrosses. Pesquisa Agropecuária Brasileira, Brasília, DF, v. 41, n. 5, p. 771778, 2006. 